\title{
Expression of rheumatoid arthritis in two ethnic Jewish Israeli groups
}

\author{
M Amit, D Guedj, A J Wysenbeek
}

\begin{abstract}
Objective-To investigate the expression of rheumatoid arthritis (RA) in Jewish Israeli patients according to ethnic origin. Methods-RA patients who were seen in a primary public rheumatology clinic were divided into two groups according to ethnic origin (Sepharadic or Askenazi) and subjected to a cross sectional study. The two groups were compared for history, physical status, and radiographic and laboratory variables. The entire study population was again divided into two groups according to formal educational level, and these were also compared for the same variables as above.
\end{abstract}

Results-The patients of Sepharadic origin had significantly more pathological recordings of pain and fatigue, and greater Ritchie scores than those of Askenazi origin. The Sepharadic group patients were younger, had a lower educational level, and were predominantly female. The more educated group recorded significantly less pathological pain and fatigue, and had smaller Ritchie scores. Functional capacity and global disease severity, assessed by physician and patient, were also reduced in the more educated group. On multiple regression analysis, ethnic origin was found to be independently related to functional class. Education was found to be independently related to the Ritchie score.

Conclusions-Disease manifestations in Jewish RA patients of Sepharadic origin are more serious compared with those in patients of Askenazi origin. In addition, low educational level is related to more severe disease manifestations in Israeli RA patients.

(Ann Rheum Dis 1996; 55: 69-72)

Expression of rheumatoid arthritis (RA) and other inflammatory and chronic diseases is influenced by several factors, including socioeconomic standing ${ }^{1-5}$ and level of formal education. ${ }^{3-9}$ Ethnic origin also exerts influence on disease expression, but less information exists on this subject. ${ }^{10}$ We have previously described the difference in expression and severity of systemic lupus erythematosus (SLE) between various ethnic Jewish Israeli groups; ${ }^{11}$ in the present cross sectional study we investigated disease expression in Israeli RA patients according to ethnic origin. We also studied the relation between disease expression and formal educational level.
Many studies of RA have been conducted in tertiary medical centres. The present study was conducted in a primary public rheumatology clinic, frequented by patients of all socioeconomic classes. All the participants were examined by the same rheumatologist.

\section{Patients and methods}

The study population consisted of 167 Jewish patients who fulfilled the revised criteria for $\mathrm{RA}^{12}$ and were seen during one year in a primary community rheumatology clinic. All the patients included in this study were seen by the same rheumatologist (DG).

Each patient was questioned about: origin (Askenazi Jewish or Sepharadic Jewish); education (number of school years); profession (score 0-4 according to skill, modified from the British Census Scale: ${ }^{13} 0=$ unskilled workers (eg dishwashers); 1 = partly skilled workers (eg waitresses); 2 = manual and non-manual skilled occupations (eg mechanics and sales persons, respectively); $3=$ managerial and other professional occupations (eg teachers); $4=$ professionals (eg doctors)); duration of morning stiffness (in minutes); severity of pain (score 0-10 visual analogue scale); fatigue (score 0-3); functional capacity (score 0-3: $0=$ normal functional capacity; $1-3=$ mild, moderate, and severe limitation in activities of daily living).

Physical examination parameters included the Ritchie index for joint tenderness (score 0-96), presence of rheumatoid nodules (score $0-1$ ), and physician's global assessment of disease severity (score 0-3).

Laboratory examinations included erythrocyte sedimentation rate (ESR), haemoglobin concentration and rheumatoid factor and antinuclear antibody (ANA) titres.

Radiographic examinations included hand and wrist radiographs, which were assessed for degree of periarticular osteopenia (score 0-2), and for severity of erosions (score 0-2).

Use of non-steroidal anti-inflammatory drugs, second line drugs, and prednisone dosage was recorded for each patient.

Patients were divided into two groups according to their ethnic origin: Askenazi Jews, and Sepharadic Jews. Jews of mixed origin were not included in this study, neither were Arabs. Patients were also classified in two groups according to their level of formal education: one group consisted of patients with fewer than eight school years; the second included patients with eight or more school years. To investigate the influence of education on disease manifestations within each ethnic 
group, patients of the two ethnic groups were also further divided into two subgroups, according to their formal educational level: eight years or fewer, and more than eight years.

\section{DATA ANALYSIS}

Groups were compared using the Wilcoxon rank sum test when data were measured on an interval scale. Nominal and ordinal data were compared by the $\chi^{2}$ test. The $\chi^{2}$ test for trend was used when appropriate. ${ }^{14}$ Multiple logistic regression analysis was used to investigate the relation between variables.

Data are presented as mean (SD) for group interval data, and as percentage of the study groups for nominal and ordinal data.

\section{Results}

The study group of 167 patients included 131 women and 36 men, mean age $59 \cdot 2$ (SD 1.1) years (range 19-87 years). Seventy four (44.3\%) of the patients were of Askenazi origin and $93(55 \cdot 7 \%)$ were of Sepharadic origin.

Table 1 Comparison between Askenazi and Sepharadic patients according to clinical and laboratory disease manifestations and to education

\begin{tabular}{|c|c|c|c|}
\hline & $\begin{array}{l}\text { Askenazi } \\
(n=74)\end{array}$ & $\begin{array}{l}\text { Sepharadic } \\
(n=93)\end{array}$ & $p$ \\
\hline $\begin{array}{l}\text { Pain }(0-10) \\
\text { Morning stiffness ( } \mathrm{min} \text { ) }\end{array}$ & $\begin{array}{c}5 \cdot 2(2 \cdot 2) \\
58 \cdot 4(54 \cdot 2)\end{array}$ & $\begin{array}{c}6 \cdot 3(2 \cdot 1) \\
66 \cdot 2(49 \cdot 4)\end{array}$ & $\begin{array}{l}<0.001 \\
\text { NS }\end{array}$ \\
\hline Fatigue $(\%)(0-3) \dagger$ & 18.9 & $43 \cdot 1$ & 0.0001 \\
\hline Functional capacity $(\%)(0-3) \dagger$ & $74 \cdot 8$ & $82 \cdot 7$ & 0.01 \\
\hline Ritchie index (0-96) & $17 \cdot 8(10 \cdot 4)$ & $25 \cdot 5(13 \cdot 2)$ & $<0.01$ \\
\hline Nodules $(\%)(0-1)+t$ & 14.9 & $19 \cdot 4$ & NS \\
\hline Disease severity $(\%) \hat{\oint}(0-3) \dagger$ & $81 \cdot 1$ & $89 \cdot 2$ & NS \\
\hline Prednisone dose (mg/day) & $4 \cdot 1(4 \cdot 3)$ & $4 \cdot 7(5 \cdot 1)$ & NS \\
\hline $\operatorname{ESR}(\mathrm{mm} / 1 \mathrm{st} \mathrm{h})$ & $60 \cdot 6(26 \cdot 3)$ & $64 \cdot 6(24 \cdot 6)$ & NS \\
\hline $\mathrm{Hb}(\mathrm{g} / \mathrm{l})$ & $12 \cdot 1(1 \cdot 2)$ & $11 \cdot 8(1 \cdot 2)$ & NS \\
\hline RF $(\%)$ & $52 \cdot 7$ & $62 \cdot 2$ & NS \\
\hline ANÄ (\%) & $56 \cdot 2$ & $66 \cdot 1$ & NS \\
\hline Osteopenia (\%) (0-2)‡ & $47 \cdot 3$ & $40 \cdot 9$ & NS \\
\hline Erosion $(\%)(0-2) \ddagger$ & $28 \cdot 4$ & $32 \cdot 3$ & NS \\
\hline Education (years) & $10 \cdot 7(3 \cdot 8)$ & $6 \cdot 6(4 \cdot 8)$ & $<0.001$ \\
\hline
\end{tabular}

Values are mean (SD) where relevant.

§Global assessment by the physician.

Osteopenia = periarticular osteopenia seen in hand and wrist radiographs; erosions = seen in hand and wrist radiographs. ESR = Erythrocyte sedimentation rate; $\mathrm{Hb}=$ haemoglobin; $\mathrm{RF}=$ prevalence of positive rheumatoid factor test; ANA = prevalence of positive antinuclear antibody test.

+Percentage of patients with score $2-3 ; \chi^{2}$ test ( $p$ for trends).

HPercentage of patients with rheumatoid nodules; $\chi^{2}$ test.

$\ddagger$ Percentage of patients with score $2 ; \chi^{2}$ test ( $p$ for trends).

Table 2 Comparison between patients with high and low educational level according to clinical and laboratory disease manifestations

\begin{tabular}{|c|c|c|c|}
\hline & $\begin{array}{l}\text { High education } \\
>8 \text { years } \\
(n=86)\end{array}$ & $\begin{array}{l}\text { Low education } \\
\leqslant 8 \text { years } \\
(n=81)\end{array}$ & $p$ \\
\hline 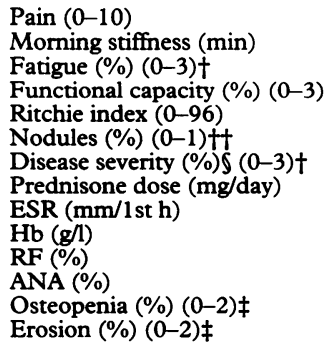 & $\begin{array}{l}5 \cdot 2(2 \cdot 3) \\
59 \cdot 4(53 \cdot 1) \\
47 \cdot 7 \\
68 \cdot 6 \\
18(11 \cdot 2) \\
12 \cdot 8 \\
80 \cdot 2 \\
4 \cdot 4(4 \cdot 6) \\
61 \cdot 2(27 \cdot 1) \\
12 \cdot 1(1 \cdot 2) \\
54 \cdot 7 \\
52 \cdot 9 \\
43 \cdot 0 \\
25 \cdot 6\end{array}$ & $\begin{array}{l}6 \cdot 4(1 \cdot 9) \\
66 \cdot 3(49 \cdot 9) \\
39 \cdot 5 \\
81 \cdot 5 \\
26 \cdot 4(12 \cdot 7) \\
22 \cdot 2 \\
91 \cdot 3 \\
4 \cdot 5(4 \cdot 9) \\
64 \cdot 6(25 \cdot 4) \\
11 \cdot 7(1 \cdot 2) \\
59 \cdot 3 \\
71 \cdot 6 \\
44 \cdot 3 \\
35 \cdot 8\end{array}$ & $\begin{array}{l}<0 \cdot 001 \\
\text { NS } \\
0 \cdot 02 \\
0 \cdot 004 \\
<0 \cdot 001 \\
\text { NS } \\
0 \cdot 04 \\
\text { NS } \\
\text { NS } \\
\text { NS } \\
\text { NS } \\
0 \cdot 02 \\
\text { NS } \\
\text { NS }\end{array}$ \\
\hline
\end{tabular}

Values are mean (SD) where relevant.

Values are mean (SD) where relevant
Global assessment by the physician.

Ostobal assessment by the physician.

Osteopenia = periarticular osteopenia seen in hand and wrist radiographs; erosions = seen in hand and wrist radiographs. ESR = Erythrocyte sedimentation rate; $\mathrm{Hb}=$ haemoglobin; $\mathrm{RF}=$ prevalence of positive theumatoid factor test; $\mathrm{ANA}=$ prevalence of positive antinuclear antibody test.

†Percentage of patients with score $2-3 ; x^{2}$ test ( $p$ for trends)

HPercentage of patients with rheumatoid nodules; $\chi^{2}$ test.

$\ddagger$ Percentage of patients with score $2 ; \chi^{2}$ test ( $p$ for trends).
Eighty six patients belonged to the higher education group, with a mean of $12.2(0 \cdot 2)$ school years (median 12 years); 81 patients belonged to the lower education group with a mean of $4.4(0.3)$ school years (median 5 years). Twenty five of the latter group had never attended school.

Patients of Askenazi origin were older than those of Sepharadic origin $(65.6(1.45)$ years $v 54.2(1.51)$ years, respectively; $\mathrm{p}<0.001)$. The two groups also differed in sex distribution: $67 \cdot 6 \%$ of the Askenazi patients were women, compared with $87.1 \%$ in the Sepharadic group $(p=0.004)$. There were fewer children per family among the Askenazi patients $(2.2(0.15))$ compared with the Sepharadic group $(4.4(0.28) ; p<0.001)$.

Table 1 shows the difference in clinical, laboratory and radiographic disease activity parameters between the two ethnic groups (Askenazi and Sepharadic Jews).

The Askenazi origin group had a higher education level than those of Sepharadic origin. Pain was less severe in the Askenazi group than in the Sepharadic group, and the proportion of patients with moderate to severe fatigue score was lower in the Askenazi group; the Ritchie index was higher in the Sepharadic origin group. There was no significant difference between the two groups regarding the other parameters, including the duration of morning stiffness, laboratory and radiographic results, and dosage of prednisone, though there was a trend for more pathological scores for most of these parameters in the Sepharadic group.

The study population was also divided into two groups according to their educational level, regardless of their origin. The two groups were compared for the variables described above (table 2). The lower education group scored significantly higher for pain, Ritchie index, proportion of patients with greater functional limitation, and proportion of patients with severe fatigue.

There was also a difference between the two groups in the proportion of patients with high scores for disease severity as assessed by the physician, which was greater in the lower education group. No significant differences were found between the two groups concerning the other variables examined, including age $(57.8(1.75)$ years in the higher education group, and $60.8(1.44)$ years in the lower education group) and gender (72.1\% women in the higher education group, and $85.2 \%$ women in the lower education group). Patients in the lower education group had more children than those in the higher education group $(2.7(0.20) v 4.2(0.31)$, respectively; $\mathrm{p}<0.001)$.

Patients were divided into subgroups according to profession and were again compared for the same variables. The less skilled patients' scores were significantly more pathological for pain, fatigue, functional capacity, Ritchie index, and history of disease severity (data not shown).

Table 3 compares the effect of education on disease manifestations within each ethnic 
Table 3 Comparison between subgroups of Askenazi and Sepharadic patients, with high ( $>8$ school years) and low educational level ( $\leqslant 8$ school years), according to clinical and radiographic disease manifestations

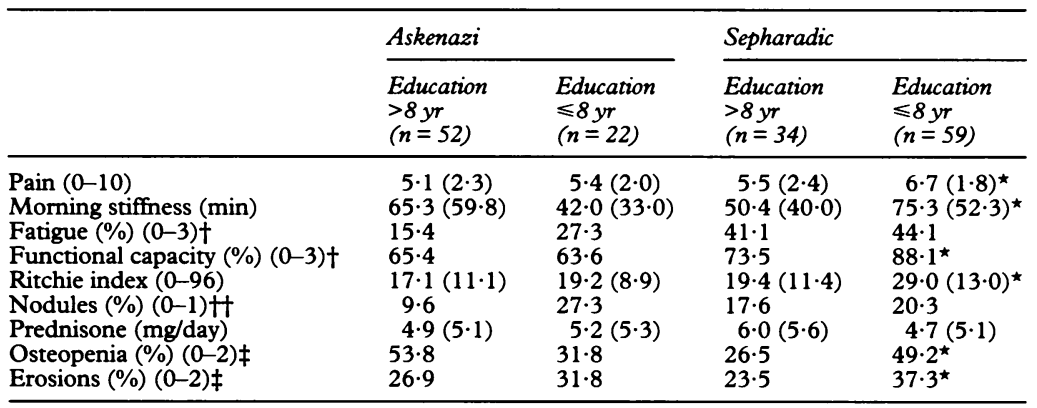

Values are mean (SD) where relevant.

Osteopenia = periarticular osteopenia seen in hand and wrist radiographs; erosions = seen in hand and wrist radiographs.

in hercentage of patients with score $2-3 ; \chi^{2}$ test ( $p$ for trends).
+Percentage of patients with rheumatoid nodules; $\chi^{2}$ test.

$\$$ Percentage of patients with score $2 ; \chi^{2}$ test ( $p$ for trends).

${ }^{\star} p<0.05$ for comparison between two educational subgroups of the same ethnic origin

Table 4 Logistic regression analysis of combined effect of education, origin, age and sex on dependent clinical variables

\begin{tabular}{|c|c|c|c|c|c|c|c|c|c|c|}
\hline \multirow[t]{2}{*}{$\begin{array}{l}\text { Independent } \\
\text { variable }\end{array}$} & \multicolumn{2}{|l|}{ Pain } & \multicolumn{2}{|c|}{ Fatigue } & \multicolumn{2}{|c|}{ Ritchie index } & \multicolumn{2}{|c|}{$\begin{array}{l}\text { Disease } \\
\text { severitys }\end{array}$} & \multicolumn{2}{|c|}{$\begin{array}{l}\text { Functional } \\
\text { capacity }\end{array}$} \\
\hline & Coeff. & $p$ & Coeff. & $p$ & Coeff. & $p$ & Coeff. & $p$ & Coeff. & $p$ \\
\hline Intercept & $0 \cdot 1$ & 0.9 & 0.7 & 0.6 & $-1 \cdot 2$ & $0 \cdot 3$ & $1 \cdot 1$ & $0 \cdot 3$ & 1.9 & $0 \cdot 1$ \\
\hline Education & 0.02 & 0.7 & 0.05 & 0.3 & 0.1 & 0.01 & 0.06 & 0.1 & 0.01 & 0.7 \\
\hline Origin & $-0 \cdot 12$ & 0.4 & $-0 \cdot 2$ & $0 \cdot 2$ & -0.08 & 0.6 & -0.03 & 0.8 & -0.5 & 0.009 \\
\hline Age (yr) & $-0 \cdot 0$ & 0.9 & -0.0 & 0.8 & 0.00 & 0.9 & -0.01 & $0 \cdot 2$ & -0.04 & 0.002 \\
\hline Sext & $1 \cdot 3$ & 0.008 & 1.0 & 0.055 & $1 \cdot 0$ & 0.02 & 0.9 & 0.06 & $0 \cdot 3$ & 0.6 \\
\hline
\end{tabular}

Global assessment by the physician

$t<1=$ female $\geqslant 1=$ male. factors mentioned, may also be related to the severity of RA, but less information exists on this subject. ${ }^{10}$ Differences in severity of disease manifestations between British and Greek RA patients, ${ }^{15}$ and between British and Spanish RA patients ${ }^{16}$ have been described. British RA patients tend to have more severe disease manifestations than Greek and Spanish patients. We have previously described the difference in SLE expression between various Jewish ethnic groups in Israel: ${ }^{11}$ patients of Sepharadic origin had more serious disease manifestations than patients of Askenazi origin, and the Sepharadic patients had a significantly lower education level. However, only ethnic origin, not education, was significantly related to disease manifestations.

In the present cross sectional study we investigated the relation between ethnic origin (Sepharadic and Askenazi) and the severity of disease expression in Jewish Israeli RA patients. We found that patients of the two ethnic groups differed mainly in clinical parameters of disease activity such as Ritchie index, severity of pain, and fatigue score, all of which were more pathological in the Sepharadic group. No differences were found between the two groups regarding the duration of morning stiffness, and the laboratory and radiographic parameters.

The two groups differed in two important demographic parameters: age (greater in the Askenazi group) and gender distribution (a greater proportion of women in the Sepharadic group). To correct for the effect of these differences on the results, we conducted a logistic regression analysis and found that origin was independently related to functional capacity. Differences in disease expression between various ethnic groups may thus be, at least in part, attributed to genetic factors. Socioeconomic and environmental factors may also contribute to such differences. Differences in disease expression between RA patients of diverse ethnic origins may have implications for RA research, which may have to be stratified accordingly.

In the present study we also investigated the relation between severity of $R A$ and formal educational level. We found that the lower education group (fewer than eight years of schooling) recorded more pathological scores for pain, fatigue, functional capacity, Ritchie index, and global assessment by physician and patient. We also compared higher educational level and lower educational level patients of the same origin, and found that within the Askenazi group there was no difference between the two educational subgroups regarding the clinical and radiographic parameters investigated, while in the Sepharadic group the lower educational level patients recorded more pathological scores for pain, duration of morning stiffness, functional capacity, and Ritchie index, compared with patients of a higher educational level. This lower education subgroup also had greater proportions of patients with severe osteopenia and severe erosions on radiographic studies, though no difference was found between the
Discussion
Rheumatoid arthritis, in common with other
inflammatory and chronic diseases, is influ-
enced by many factors, including environ-
mental, genetic, ${ }^{2}$ and socioeconomic. ${ }^{3-5}$
Many studies have investigated the impact of
education on disease activity in RA, and found
educational level to be inversely related to the
severity of disease expression and to
prognosis. ${ }^{3-9}$ Ethnic origin, like the other

Discussion
Rheumatoid arthritis, in common with other
inflammatory and chronic diseases, is influ-
enced by many factors, including environ-
mental, genetic, ${ }^{2}$ and socioeconomic. ${ }^{3-5}$
Many studies have investigated the impact of
education on disease activity in RA, and found
educational level to be inversely related to the
severity of disease expression and to
prognosis. $^{3-9}$ Ethnic origin, like the other

Discussion
Rheumatoid arthritis, in common with other
inflammatory and chronic diseases, is influ-
enced by many factors, including environ-
mental, genetic, ${ }^{2}$ and socioeconomic. ${ }^{3-5}$
Many studies have investigated the impact of
education on disease activity in RA, and found
educational level to be inversely related to the
severity of disease expression and to
prognosis. $^{3-9}$ Ethnic origin, like the other

Discussion
Rheumatoid arthritis, in common with other
inflammatory and chronic diseases, is influ-
enced by many factors, including environ-
mental, genetic, ${ }^{2}$ and socioeconomic. ${ }^{3-5}$
Many studies have investigated the impact of
education on disease activity in RA, and found
educational level to be inversely related to the
severity of disease expression and to
prognosis. $^{3-9}$ Ethnic origin, like the other

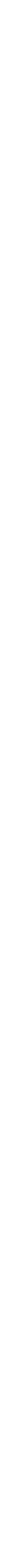


Sepharadic patients with higher educational level and the Askenazi patients. A similar pattern was observed in SLE patients of Sepharadic and Askenazi origins in Israel. ${ }^{11}$ Logistic regression analysis showed that the formal educational level was independently related to Ritchie index and to functional capacity. These results resemble those of previous studies. . $^{3-9}$

The present study was conducted in a primary community rheumatology clinic, where patients of all socioeconomic classes are seen. Health services in Israel are public and equally accessible for all socioeconomic and ethnic groups. This statement is also true for secondary and tertiary medical centres in Israel. Private medical facilities are not widely used in Israel. We believe, therefore, that our results reflect the difference in severity of RA manifestations between subgroups of the Jewish population in Israel. As all the participants in this study were examined by the same rheumatologist, possible bias from between observer differences was excluded.

The influence of ethnic origin on the prognosis of RA remains to be investigated. Proof of the existence of such an influence would have important implications for both treatment and rehabilitation of RA patients.

1 Harris E D Jr. Clinical features of rheumatoid arthritis. In: Kelley W N, Harris E D Jr, Ruddy S, Sledge C B, eds. Textbook of rheumatology, 4th edn. Philadelphia: Saunders, 1993; 875-6.
2 Felson D T. Epidemiology of the rheumatic diseases. In: McCarty D J, ed. Arthritis and allied conditions, 12th edn. Philadelphia: Lea and Febiger, 1993; 21-4.

3 Leigh J P, Fries J F. Education level and rheumatoid arthritis: evidence from five data centers. $\mathcal{f}$ Rheumatol 1991; 18: 24-34.

4 Leigh J P, Freis J F. Occupation, income and education as independent covariates of arthritis in four national probability samples. Arthritis Rheum 1991; 34: 984-96.

5 Jacobson L, Lindgarde F, Manthorpe R, Ohlsson K. Effect of education, occupation and some lifestyle factors on common rheumatic complaints in a Swedish group aged 50-70 years. Ann Rheum Dis 1992; 51: 835-43.

6 Verbrugge L M, Gates D M, Ike R W. Risk factors for disability among U.S. adults with arthritis. $f$ Clin disability among U.S. ad

7 Callahan L F, Pincus T. Formal education level as a significant marker of clinical status in rheumatoid arthritis. Arthritis Rheum 1988; 31: 1346-57.

8 Hannan M T, Anderson J J, Pincus T, Felson D T. Educational attainment and osteoarthritis: Differential associations with radiographic changes and symptom reporting. F Clin Epidemiol 1992; 45: 139-47.

9 Pincus T, Callahan L F. Formal education as a marker for increased mortality and morbidity in rheumatoid arthritis. f Chron Dis 1985; 38: 973-84.

10 Vlachoyiannopoulos P G, Moutsopoulos H M. Rheumatoid arthritis in south-east Europe. Baillieres Clin Rheumatol arthritis in south

11 Wysenbeek A J, Leibovici L, Weinbergwer A, Guedj D. Expressions of systemic lupus erythematosus in various ethnic Jewish Israeli groups. Ann Rheum Dis 1993; 52: 268-71.

12 Arnett F C, Edworthy S M, Bloch D A, et al. The American Rheumatism Association 1987 revised criteria for the classification of rheumatoid arthritis. Arthritis Rheum 1988; 19: 315-24.

13 Esdaile J M, Sampalis J S, Lacaille D, Danoff D. The relationship of socioeconomic status to subsequent health status in systemic lupus erythematosus. Arthritis Rheum 1988; 31: 423-8.

14 Brown B W, Hollander M. A test for trend in proportions. In: Statistics. A biomedical introduction. New York: John Wiley and Sons, 1977; 211-6.

15 Drosos A A, Lanchbury J S, Panayi G S, Moutsopoulos H M. Rheumatoid arthritis in Greek and British patients: a comparative clinical, radiologic, and serologic study. Arthritis Rheum 1992; 35: 745-8. 16 Ronda E, Ruiz M T, Pascual E, Gibson T. Differences
between Spanish and British patients in the severity of rheumatoid arthritis: comment on the article by Drosos et al [letter]. Arthritis Rheum 1994; 37: 147-52. 